\title{
RECENT DEVELOPMENTS IN CALCIUM TREATMENT IN STEELMAKING: A SOURCE OF TECHNICAL EFFICIENCY AND COST-SAVINGS*
}

\author{
Sébastien Gérardin ${ }^{1}$ \\ Marc Schatz ${ }^{2}$ \\ Claude Lenoir ${ }^{3}$ \\ Alvaro Andres Bustos Cainarca ${ }^{4}$
}

\begin{abstract}
Developed for more than 30 years, continuously improved, cored wire is nowadays a reliable solution for the improvement of sustainability, safety, health and doing quality and cost saving. Cored wire allows the addition of ferroalloys and treatment of liquid steel, especially concerning the calcium treatment. Amongst all the processes in secondary metallurgy, calcium treatment is certainly the most critical one before casting. Besides the traditional $\mathrm{CaSi}$ and $\mathrm{CaFe}$ wires, new types of wire have been designed for becoming the new reference in calcium treatment. PapCal (calcium insulated wire) and HDx (high density calcium wire) are a very versatile range of products. Indeed, according to the steelmaking process parameters (steel grade, treatment temperature, ladle size, calcium content targeted in tundish and even injection conditions), their technical specifications may be adapted in order to optimize the calcium treatment as high as possible.
\end{abstract}

Keywords: Calcium treatment; High density calcium; Cost savings; Total cost of ownership.

PhD in Metallurgy, VP of Research Development \& Innovation, AFFIVAL, Solesmes, France.

Bachelor of Business Administration, VP of Sales and Marketing, AFFIVAL, Solesmes, France.

Chairman, AFFIVAL, Solesmes, France.

Bachelor of Management, Area Manager for Latin America \& Southern Europe, AFFIVAL, Solesmes, France. 


\section{INTRODUCTION}

Developed for more than 30 years, continuously improved, cored wire is nowadays a reliable solution for the improvement of sustainability, safety, health and doing quality and cost saving. Cored wire allows the addition of ferroalloys and treatment of liquid steel, especially concerning the calcium treatment.

Although the technology may appear pretty simple, the quality of a wire depends on numerous technical process parameters: consistency of powder metric weight, powder blends, lock seaming, and packaging. Initially designed for the addition of CaSi for calcium treatment in secondary metallurgy, cored wire is widely used for any sort of applications and processes (steel de-oxidation, addition and Trimming, machinability improvement, re-nitriding, inclusion shape control) with any kind of chemical elements.

\section{MATERIAL AND METHODS}

The calcium content in steel is the most common measurement in order to estimate the calcium treatment effectiveness. Calcium content is measured thanks OES method (Optical Emission Spectroscopy). This method is based on the detection of radiation emitted by the atoms which have been preliminary excited after vaporization made by an arc spark discharge. It is important to note that Ca content measured by OES corresponds to the total $\mathrm{Ca}$ content in steel, that is to say the sum, at cast temperature, of dissolved $\mathrm{Ca}$ in steel, $\mathrm{Ca}$ contained in sulfide and oxide microinclusions. In first approximation, it can be considered that the higher the total $\mathrm{Ca}$ content is, the higher the $\mathrm{Ca}$ content in oxide inclusions is.

Samples (lollypops) are taken by the steel maker 2 min after calcium injection in the ladle and then in tundish. Ca yield can be then calculated by dividing $\mathrm{Ca}$ content measured in steel (in ppm) by added $\mathrm{Ca}$ content (length of injected cored wire multiplied by calcium metric weight, divided by tons of steel in ladle) (in $\mathrm{g}$ per ton , that is to say in ppm).

\section{RESULTS AND DISCUSSION}

Amongst all the processes in secondary metallurgy, calcium treatment is certainly the most critical one before casting. The number of publications written on this topic in literature sounds as an evidence of this. Those papers deal with numerous domains as various as the phenomena involved in inclusion shape control by calcium, chemical composition, size and density of inclusion population, steel cleanliness as well mechanisms of deposit formation in SEN (Submerged Entry Nozzle). Indeed, castability is directly related to the inclusion population in steel beforehand treated by calcium.

In the case of aluminum-killed steels, the endogenous inclusions are alumina $\mathrm{Al}_{2} \mathrm{O}_{3}$ or spinels $\mathrm{Al}_{2} \mathrm{O}_{3}-\mathrm{MgO}$. Figure 1 shows these alumina inclusions are solid inclusions below casting temperature. This will irredeemably lead to clogging in continuous caster since $\mathrm{Al}_{2} \mathrm{O}_{3}$ react with $\mathrm{SEN}$ refractory. To avoid any troubles during casting, inclusions must be liquid. Only a small area on phase diagram (Fig. 1) shows liquid inclusions whose chemistry is around $(\mathrm{CaO})_{12 \cdot} \cdot\left(\mathrm{Al}_{2} \mathrm{O}_{3}\right)_{7}$. Ternary MgO-CaO- $\mathrm{Al}_{2} \mathrm{O}_{3}$ diagram shows also in this area that inclusions containing a small $\mathrm{MgO}$ content may present a lower melting temperature. 


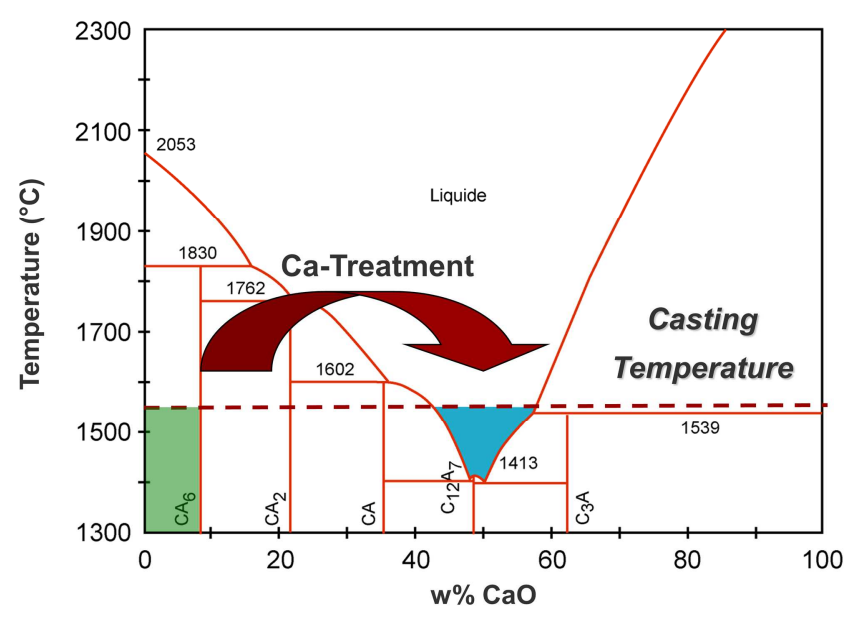

Fig 1: $\mathrm{Al}_{2} \mathrm{O}_{3}-\mathrm{CaO}$ phase diagram

In those conditions, calcium treatment does clearly appear as a tough process to be performed correctly; especially sharp as industrial conditions in secondary metallurgy are so various. Indeed, many parameters may drastically impact the calcium treatment such as chemical composition of slag (especially the contents of $\mathrm{FeO} /$ $\mathrm{MnO}$ which are very reducible oxides), aluminum, silicon, oxygen and sulfur contents in liquid steel, temperature of molten steel and so on. As previously mentioned, lots of studies deal with this topic, but not many of them analyze the ways to add calcium into liquid steel. This may however be a real challenge since calcium does violently react in liquid steel (calcium presents a boiling temperature much lower than molten steel).

This study shows the latest improvements made in this domain of secondary metallurgy.

\subsection{Best Practices for Calcium Treatment}

Except uncommon applications such as addition through a lance, calcium is usually fed into liquid steel thanks to cored wire. The most common products are nowadays $\mathrm{CaSi}, \mathrm{CaFe}$ or even $\mathrm{AlCaFe}$ cored wires which are used according to chemical specifications of steel grades. Indeed, CaFe wires would be, for instance, preferred to CaSi wires because of Si-pick-up prohibited for low Silicon content steel grades.

Nevertheless, in order to succeed in a right calcium treatment, a special attention should be paid into the cored wire itself as well the injection conditions of this wire. That's why AFFIVAL does continuously conduct R\&D projects on both aspects: calcium-based wires and feeding equipments.

Besides the traditional CaSi and CaFe wires, new types of wire have been designed for becoming the new reference in calcium treatment. These new wires, which are obviously patented, show the main feature to be intrinsically composed of a thermal insulation layer. Figure 2 shows a schematic view of such a wire. The insulation layer is sandwiched between two steel strips. 


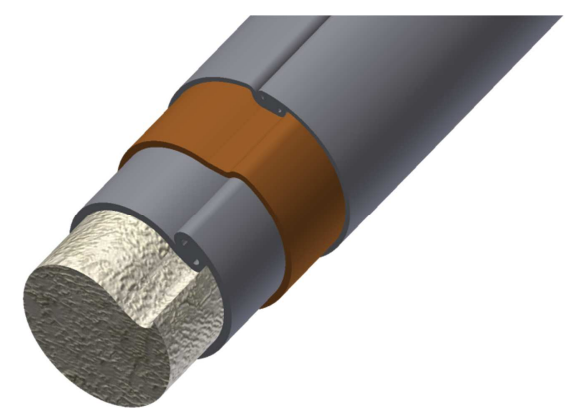

Fig 2: Calcium insulated wire (PapCal®)

Since pure calcium does violently react while fed into liquid steel, the targeted aim is to reduce, as long as possible, the exposure of calcium core to temperature rise. It has been shown that the explosion of calcium reaching its boiling temperature was delayed by one second (compared to a standard pure calcium wire) in case of a wire made of two steel strips (total thickness about $0.7 \mathrm{~mm}$ ) and an thermal insulation of $0.4 \mathrm{~mm}$ thick. The wire integrity being extended, calcium is released much more deeply in liquid steel. This does obviously lead to enhance the calcium treatment performances (gaseous calcium bubbles have more time to react with endogenous inclusions).

Core of the wire may be made of traditional calcium granules (compacted in the inner steel strip) or, of an extruded calcium wire. The latter may then wrapped directly by the thermal insulation and the outer steel strip. This kind of wire (HDx) shows very good mechanical properties which allows to improve the conditions of injection.

PapCal and HDx are a very versatile range of products. Indeed, according to the steelmaking process parameters (steel grade, treatment temperature, ladle size, calcium content targeted in tundish and even injection conditions), their technical specifications may be adapted in order to optimize the calcium treatment as high as possible. Thereby, numerous specifications are possible with a combination of three following features:

- Calcium metric weight $(55,70$ or $85 \mathrm{~g} / \mathrm{m})$

- Number of steel envelops (1 or 2$)$

- Thickness of steel casing (from 0.5 to $1.1 \mathrm{~mm}$ )

All of these wires are composed of a thermal insulation layer.

Figure 3 shows metallurgical results obtained with an HDx wire (ref. K0906) made of one steel strip, $0.6 \mathrm{~mm}$ thick, and a calcium metric weight about $70 \mathrm{~g} / \mathrm{m}$. Tests have been run on Al-killed and Al/Si-killed steel grades tapped in 160tons ladles. Standard calcium treatments were respectively performed with $\mathrm{CaFe}$ and $\mathrm{CaSi}$ wires.

\section{all results $\quad$ Al-killed steel grades $\quad$ Al/Si-killed steel grades}

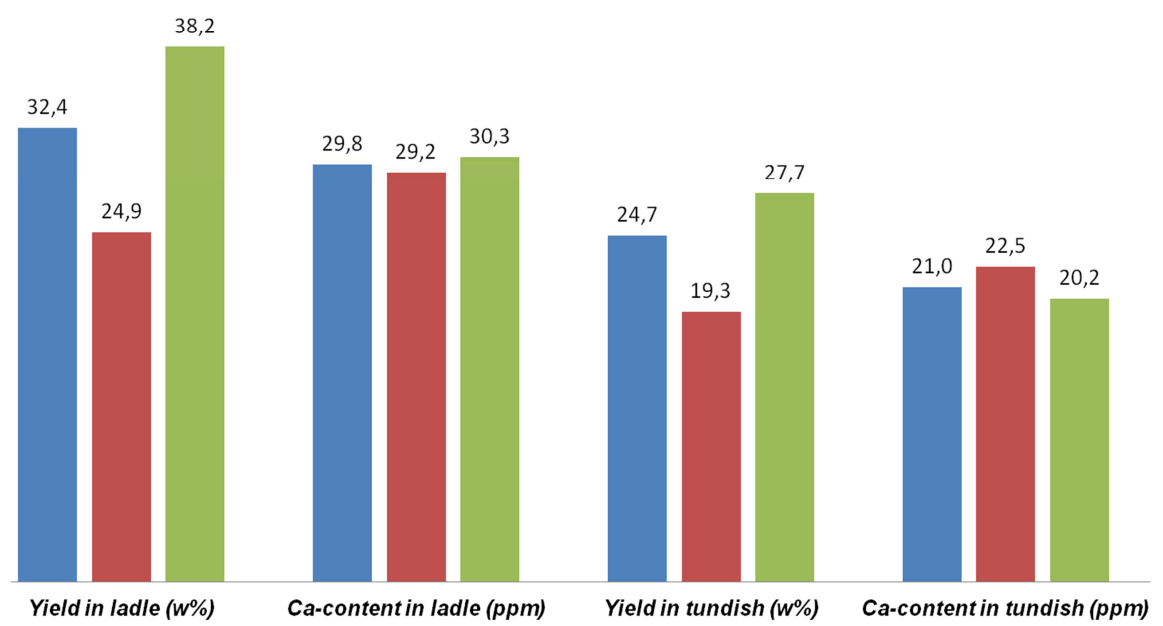

Fig 3: Metallurgical performances of K0906 wire 
Concerning Al-killed steels, Ca-yield was about $13 \%$ with $\mathrm{CaFe}$ wire while Ca-yield is about $25 \%$ with K0906 (+90\% improvement) in the same conditions (minimum Cacontent in tundish: 20ppm). In a comparable way for Al/Si-killed steels, CaSi recovery was $23 \%$ while K0906 performances are higher than 38\% (+65\% improvement). Thanks to these metallurgical performances, total treatment costs have been tremendously decreased by $32 \%$ although standard wires are reputed to be cheap. Another technical advance concerns the feeding equipment. AFFIVAL develops the patented concept of Vertical Injection with a new type of feeding machine. Installed right above the ladle, the equipment is able to straight and simultaneously to feed the wire into molten steel. In these conditions, wire overcomes the ferrostatic pressure and calcium is then released very deeply in ladle. A combined use of this equipment with new calcium wires, PapCal or HDx, represents the State-of-the-Art in calcium treatment. Obviously, decreasing the consumption of calcium while steelmaking process is secured with low standard deviation, leads to treatment costs as low as possible for the end-user.

\section{CONCLUSION}

A failure in calcium treatment may have catastrophic consequences. It is thereby necessary to secure the process with reliable solutions. Sources of technical efficiency, these new developments do also perfectly fit the approach of Total Cost of Ownership (TCO). Although more expensive than standard products, these new wires PapCal and HDx enable to bring cost-savings to the end-users by reducing drastically the consumptions and securing the steelmaking process. 